\title{
Estrutura populacional e tendências genéticas e fenotípicas da raça Guzerá no Nordeste do Brasil
}

\section{Population structure and genetic and phenotypic trends of Guzera in Northeast of Brazil}

\author{
SANTOS, Leonardo Hunaldo ${ }^{1 *}$; OLIVEIRA, Sônia Maria Pinheiro de ${ }^{1}$; MALHADO, \\ Carlos Henrique Mendes ${ }^{2}$; CARNEIRO, Paulo Luiz de Souza ${ }^{2}$; MARTINS FILHO, \\ Raimundo $^{3}$; LÔBO, Raimundo Nonato Braga ${ }^{4}$; RODRIGUES, Daliane da Silva ${ }^{1}$
}

\author{
${ }^{1}$ Universidade Federal do Ceará, Centro de Ciências Agrárias, Departamento de Zootecnia, Fortaleza, \\ Ceará, Brasil. \\ ${ }^{2}$ Universidade Estadual do Sudoeste da Bahia, Centro de Ciências Biológicas, Departamento de Ciências \\ Biológicas, Jequié, Bahia, Brasil. \\ ${ }^{3}$ Universidade Estadual do Ceará, Faculdade de Veterinária, Departamento de Medicina Veterinária, \\ Fortaleza, Ceará, Brasil. \\ ${ }^{4}$ Embrapa Caprinos e Ovinos, Setor de Melhoramento Animal, Sobral, Ceará, Brasil. \\ *Endereço para correspondência: leohunaldo@yahoo.com.br
}

\section{RESUMO}

Objetivou-se avaliar a estrutura populacional e a relação desta com o progresso genético ocorrido em características de crescimento em rebanhos da raça Guzerá do Nordeste do Brasil. Foram utilizadas informações de pedigree e dados do peso corporal ajustado para 205, 365 e 550 dias de idade de animais nascidos no período de 1976 a 2007. O intervalo médio de geração por passagem gamética foi de 7,9 \pm 4,4 anos, assim estratificado: Pai-Filho (7,5 $\pm 4,5$ anos); Pai-Filha $(7,9 \pm 4,8)$; Mãe-Filho $(7,8 \pm 4,2)$ e Mãe-Filha $(7,9 \pm 3,9$ anos). O coeficiente de endogamia apresentou tendência a crescer da segunda até a sétima geração, a passar de $0,17 \%$ para $2,06 \%$, mas, ao se considerar apenas os animais endogâmicos, observou-se que o coeficiente médio de endogamia diminuiu, de $15,66 \%$ para $6,75 \%$ no período. O intervalo de geração foi alto. Para reduzi-lo é recomendável a utilização de touros jovens. O tamanho efetivo de população da raça na região foi entre 197 e 674 animais. Se analisado juntamente com a tendência de redução da endogamia nas últimas três décadas, evidencia existir potencial para ganho genético por seleção na raça, visto que o coeficiente de herdabilidade do peso corporal aos 365 e 550 dias de idade foi de tamanho moderado. Pela análise da tendência do ganho genético nas características do período avaliado, constatou-se que foi pequena diante de ganho fenotípico alto, o que indica que o progresso fenotípico observado foi decorrente, em sua maior parte, das melhorias realizadas no manejo.

Palavras-chave: bovino, endogamia, ganho genético, pedigree, tamanho efetivo.

\section{SUMMARY}

The aim of this work was to evaluate the relationship of the population structure with the observed genetic progress for growth traits to Guzera beef cattle raised in the Northeast Region of Brazil. Pedigree data and weights adjusted to 205; 365 and 550 days of age of animals born from 1976 to 2007 were used. The intervals of generations per gamete passage were: 7.5 \pm 4.5 (Father-Son), 7.9 \pm 4.8 (FatherDaughter), 7.8 \pm 4.2 (Mother-Son), 7,9 \pm 3.9 (Mother-Daughter), with a mean interval of $7.9 \pm 4.4$ years. The inbreeding coefficient showed the greatest growth from the second to the seventh generation, when increased from $0.17 \%$ to $2.06 \%$, however, the average inbreeding in inbred animals decreased from $15.66 \%$ to $6.75 \%$ during the same period. The effective size presented values between 197 and 674 and along with the low inbreeding, they evidenced great potential for genetic gain. The 
generation interval was high, recommending the use of young bulls for decrease this interval and increase the genetic gains. The heritabilities indicate the possibility to reach genetic gains by selecting animals mainly for weights at 365 and 550 days of age. The significantly phenotypic gains should be attributed to improvements in the environment.

Keywords: bovine, effective size, genetic gain, inbreeding, pedigree.

\section{INTRODUÇÃO}

O Nordeste é pioneiro na criação de bovinos de corte. Sua pecuária é composta principalmente por animais zebuínos mestiços e puros, na qual prevalece a criação a pasto (CAIRES et al., 2009). Entre os zebuínos mais bem adaptados a esta região, destacam-se os da raça Guzerá que apresentam boa adaptabilidade e desempenho na produção de leite e carne. Pacheco et al. (2008) salientaram o crescente interesse pela criação ou utilização dessa raça nos diferentes sistemas de produção.

Programas de melhoramento genético têm sido realizados para desenvolver a produção de bovinos de corte no Nordeste (YOKOO et al., 2012). Tais programas seguem algumas etapas, a saber: seleção dos indivíduos que serão utilizados como pais da próxima geração; escolha do sistema de acasalamento e introdução de novo material genético (variabilidade genética). Antes desse processo, existe a necessidade da realização de avaliação genética de animais das raças a serem exploradas, $o$ que disponibiliza critérios que promovem de forma eficiente o melhoramento das mesmas (MADUREIRA, et al., 2009).

Outro aspecto importante é o estudo de pedigree, útil na avaliação de diversidade genética e na análise da estrutura populacional (FARIA et al., 2002; VERCESI FILHO et al., 2002a, 2002b).
Essas informações são imprescindíveis também para elucidar o histórico genético dos rebanhos (VARELA et al., 2005).

Em relação à eficiência de programas de melhoramento animal, são indispensáveis a estimação de componentes de (co)variâncias, covariâncias e herdabilidades acuradas (YOKOO et al., 2007). Quanto ao progresso genético, é necessário avaliar as tendências genéticas, fenotípicas e de ambiente em características de importância econômica, cujos resultados podem servir como elementos norteadores de ações futuras para melhorar a produção animal na região.

Vários métodos de estimação dos parâmetros genéticos têm sido discutidos para auxiliar os processos de avaliação genética, assim como novas abordagens sobre o estudo da estrutura das populações. Entretanto, poucas pesquisas têm abordado as possíveis relações entre a estrutura populacional e o progresso genético em características de importância econômica nos rebanhos (MALHADO et al., 2008a).

Assim, objetivou-se avaliar a relação da estrutura populacional com o progresso genético, ao longo do tempo, em zebuínos da raça Guzerá, criados no Nordeste, e fornecer subsídios para programas de melhoramento genético, preservação e/ou expansão da raça.

\section{MATERIAL E MÉTODOS}

Foram utilizados registros do controle de desenvolvimento ponderal de animais da raça Guzerá, criados no Nordeste, relativos ao período de 1976 a 2007 (Tabela 1), disponibilizados pela Associação Brasileira dos Criadores de Zebuínos (ABCZ). Tais dados fazem parte do Controle de Desenvolvimento Ponderal, efetuado pela Associação 
Rev. Bras. Saúde Prod. Anim., Salvador, v.13, n.4, p.1032-1043 out./dez., 2012 http://www.rbspa.ufba.br ISSN 15199940

Brasileira dos Criadores de Zebuínos (ABCZ).

As características de crescimento utilizadas foram: peso aos 205 (P205),
365 (P365) e 550 (P550) dias de idade. Os pesos foram ajustados pela própria ABCZ.

Tabela 1. Estrutura de dados no arquivo analisado para os pesos (kg) aos $205(\mathrm{P} 205)$, 365 (P365) e 550 (P550) dias de idade de zebuínos da raça Guzerá do Nordeste brasileiro

\begin{tabular}{lrrr}
\hline Item & P205 & P365 & \multicolumn{1}{c}{ P550 } \\
\hline $\mathrm{N}^{\circ}$ de pesagens totais & 22.160 & 15.388 & 11.030 \\
$\mathrm{~N}^{\circ}$ de pesagens utilizadas & 16.714 & 12.015 & 8.189 \\
$\mathrm{~N}^{\circ}$ de animais na matriz de parentesco & 25.572 & 19.143 & 13.718 \\
$\mathrm{~N}^{\circ}$ de grupos de contemporâneos & 2.210 & 1.388 & 1.011 \\
\hline
\end{tabular}

O programa ENDOG (GUTIÉRREZ \& GOYACHE, 2005) foi utilizado para a análise da genealogia e para a estimação dos parâmetros genéticos populacionais, com base na probabilidade de origem dos genes, tamanho efetivo de população $(\mathrm{Ne})$ e intervalo médio de geração. $\mathrm{O} \mathrm{Ne}$ foi estimado em consideração dos oito períodos de quatro anos, com os dados de 1976 a 2007. Utilizou-se ainda a taxa de variação dos coeficientes médios de endogamia entre gerações sucessivas, conforme a fórmula:

$$
N_{e}=\frac{1}{2 \Delta F}
$$

Em que, $\Delta \mathrm{F}$ é o aumento da endogamia e é representado por:

$$
\Delta F=\frac{F_{t}-F_{t-1}}{1-F_{t-1}}
$$

Em que $F_{t}$ é o coeficiente médio de endogamia, estimado na geração atual; e $\mathrm{F}_{\mathrm{t}-1}$ é o coeficiente médio de endogamia estimado na geração anterior. $O$ ENDOG também foi utilizado para calcular o número efetivo de fundadores que representa o número de animais com igual contribuição, que produziria a mesma variabilidade genética encontrada na população estudada (MALHADO et al., 2008b).

Para avaliar a concentração de animais e genes originais, foi utilizada a fórmula a seguir desenvolvida por Boichard et al. (1997):

$$
f_{e}=1 / \sum_{k=1}^{f} q_{k}^{2}
$$

Em que $\mathrm{q}_{\mathrm{k}}$ é a probabilidade do gene originar-se do ancestral k. O cálculo é feito ao se utilizar os coeficientes médios de relação (ARC) dos indivíduos fundadores. $\mathrm{O}$ parâmetro $f_{e}$ calculado equivale àquele no qual a população referência utilizada apresenta pedigree completo.

$\mathrm{O}$ número efetivo de ancestrais $\left(\mathrm{f}_{\mathrm{a}}\right)$ foi calculado de maneira similar ao número efetivo de fundadores:

$$
f_{a}=1 / \sum_{j=1}^{a} q_{j}^{2}
$$

Em que $q_{j}$ é a contribuição marginal de um ancestral j, que, por sua vez, é a contribuição genética dada por um ancestral, não explicada por outros já escolhidos. Esses dois últimos parâmetros populacionais são inicialmente calculados ao se ter como referência apenas os animais do 
pedigree com ambos os pais conhecidos.

O intervalo médio de gerações das quatro passagens gaméticas foi estimado com o auxílio do ENDOG, a partir das relações: pai-filho, pai-filha, mãe-filho e mãe-filha. $\mathrm{Na}$ elaboração do arquivo de trabalho para estimação dos parâmetros genéticos foram consideradas quatro épocas de nascimento: janeiro a março, abril a junho, julho a setembro e outubro a dezembro.

Para a modelagem, foram criados grupos de contemporâneos (GC), os quais reuniam os animais do mesmo sexo, fazenda, regime alimentar, época e ano de nascimento. Foram eliminados os registros referentes à $\mathrm{GC}$ com menos de quatro observações.

Os componentes de (co)variância foram obtidos em análises univariadas, com uso do modelo animal, segundo a metodologia da Máxima Verossimilhança Restrita Livre de Derivadas (REML). Para tanto, utilizou-se ainda $O$ programa computacional MTDFREML, desenvolvido por Boldman et al. (1995).

O modelo utilizado para P205 incluiu os efeitos aleatórios genético aditivo, direto e materno e de ambiente permanente materno, além do efeito fixo de GC e da covariável idade da vaca ao parto (anos). Consideraram-se efeitos linear e quadrático e admitiu-se a (co)variância entre os efeitos direto e materno igual a zero $\left(\sigma_{\mathrm{am}}=0\right)$. Para P365 e P550, foram considerados os mesmos efeitos fixos, porém, apenas o efeito genético aditivo direto como efeito aleatório.

As estimativas de tendências genética, fenotípica e de ambiente dos pesos avaliados na raça Guzerá, no período de 1978 a 2007 no Nordeste, foram obtidas com o uso da regressão linear ponderada da média dos valores genéticos e fenotípicos dos pesos padronizados e solução dos GC, respectivamente, sobre o ano de nascimento. Esses dados, por sua vez, foram sistematizados por meio do programa Microsoft ${ }^{\circledR}$ Excel 2007.

\section{RESULTADOS E DISCUSSÃO}

As médias e os desvios-padrão dos pesos P205, P365 e P550 foram $147,58 \pm 35,03 \mathrm{~kg}, \quad 201,39 \pm 52,13 \mathrm{~kg} \quad \mathrm{e}$ $261,72 \pm 76,54 \mathrm{~kg}$, respectivamente. De maneira geral, as médias dos pesos aqui observadas foram superiores às mencionadas na literatura para a mesma raça (PIMENTA FILHO et al., 2001; MUCARI \& OLIVEIRA, 2003).

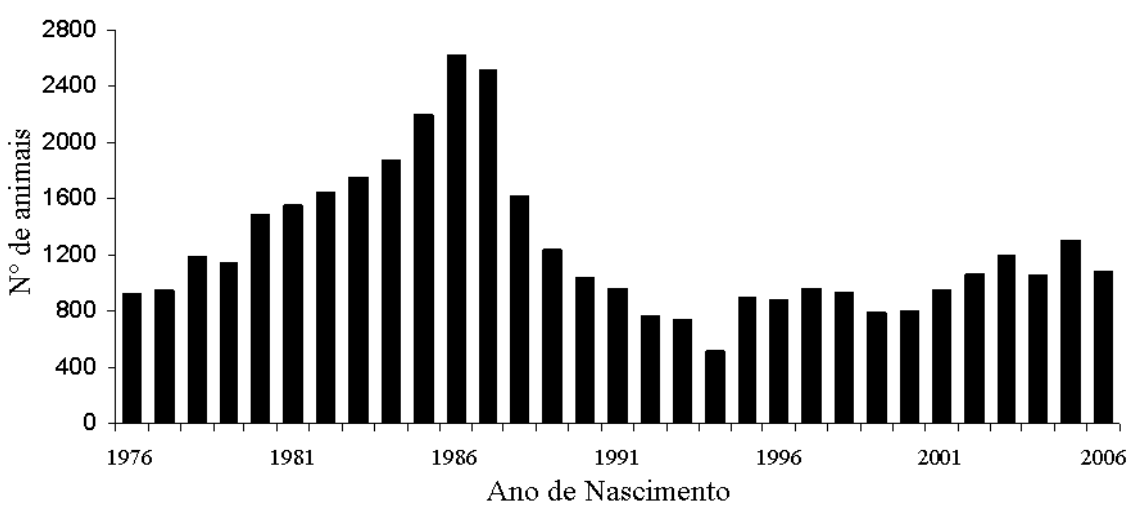

Figura 1. Número de animais nascidos da raça Guzerá do nordeste brasileiro no período de 1976-2006 
No período de 1976 a 1986, o número de animais nascidos por ano apresentou grande ascensão, quase triplicou, ao atingir 2.615 em 1986, o que indica uma possível valorização da raça (Figura 1 ). Logo após esse período, o número de nascimentos diminuiu, de modo a alcançar 512 em 1994, mas voltou a aumentar e manteve praticamente uma constância até 2006, quando foram registrados 1.080 animais da raça Guzerá no Nordeste.

O valor médio do intervalo de geração por passagem gamética foi de $7,9 \pm 4,4$ anos, assim estratificado: 7,5 $\pm 4,5$ anos (Pai-Filho), 7,9 $\pm 4,8$ anos (Pai-Filha),

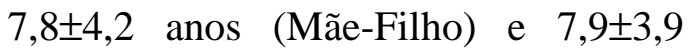
anos (Mãe-Filha). Valores próximos aos dessa pesquisa foram obtidos por Vercesi Filho et al. (2002a; 2002b), que constataram médias de 7,32 e 7,14 (paifilho), 7,64 e 7,25 (pai-filha), 7,43 e 7,20 (mãe-filho), 7,72 e 7,09 anos (mãefilha). Os valores médios encontrados pelos autores foram iguais a 7,53 e 7,17 anos, para animais das raças Indubrasil e Tabapuã, respectivamente.

De maneira geral, os intervalos de geração aqui observados foram altos, 0 que pode causar redução do ganho genético anual em características de importância econômica sob seleção. Esse fato implicaria em menor retorno econômico na atividade, consequentemente, a raça precisaria ser submetida a um programa de melhoramento genético na região, com vista à obtenção de precocidade. Malhado et al. (2008b) apresentam como alternativa para redução de intervalos de geração, a utilização de touros jovens, avaliados principalmente para menor intervalos pai-filho e paifilha.

O tamanho efetivo ( $\mathrm{Ne}$ ) aumentou de 150 em 1976 para 817 em1987. Após esse período houve um decréscimo até 1992, ano em que se registra Ne de 252. Em seguida houve outro acréscimo menos acentuado que atingiu 563 no ano de 2007 (Figura 2). Esses valores são superiores aos relatados por Vercesi Filho et al. (2002b), que encontraram tamanho efetivo de 42 para o rebanho também zebuíno da raça Indubrasil registrado no Brasil, no período 19941998. Essas duas raças apresentam similaridade quanto a sua importância no cenário pecuário.

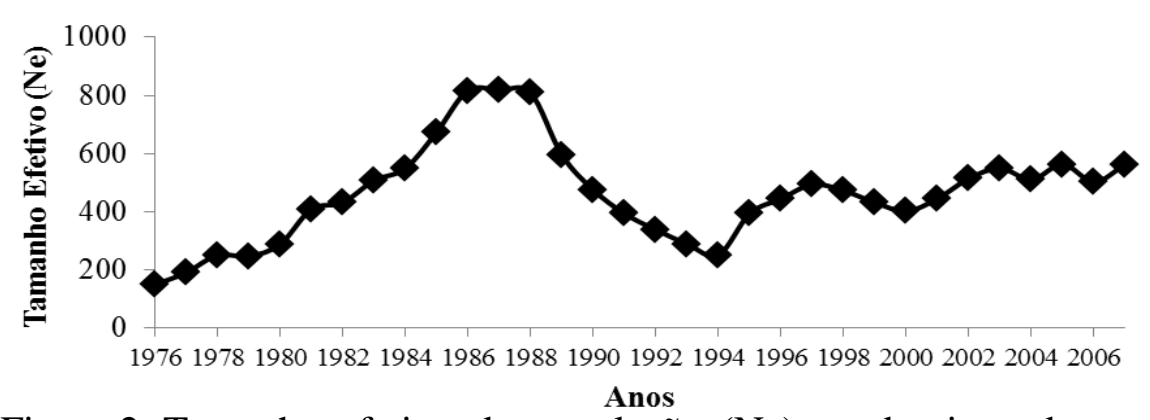

Figura 2. Tamanho efetivo de população $(\mathrm{Ne})$ em bovinos da raça Guzerá do Nordeste brasileiro, no período de 1976 a 2007

Observou-se que, quando o tamanho efetivo apresentou os maiores valores nos anos de 1986, 1987 e 1988, houve picos de ganhos genéticos para as características avaliadas (Figura 3A, B e C). Carneiro et al. (2009) afirmaram que, ao se utilizar seleção em populações com pequenos tamanhos 
efetivos para seleção, os resultados podem ser influenciados pela oscilação genética, o que pode resultar em grandes variações nos ganhos genéticos esperados.

O coeficiente médio de endogamia atingiu $1,96 \%$ na oitava geração, no entanto, a média dos animais endogâmicos decresceu de 15,66\% para $6,58 \%$ nesta geração (Tabela 2). Resultados semelhantes foram relatados por Malhado el al. (2008b), quando analisaram dados da raça Nelore na Bahia, cujo coeficiente de endogamia médio aumentou de $0,8 \%$, na segunda geração, para $1,57 \%$ na sétima, mas, a média de $\mathrm{F}$ dos animais endogâmicos diminuiu de $16,76 \%$, na segunda geração, para 3,85\%, na sétima. Esses autores citaram que tais resultados evidenciam que a endogamia nos rebanhos é baixa, fato explicado pelo aumento do tamanho efetivo nos últimos períodos.

Tabela 2. Número de animais, valores de coeficiente de endogamia do rebanho e média de F (Endogamia) para animais endogâmicos da raça Guzerá do Nordeste

\begin{tabular}{lcrcc}
\hline Geração & Período & $\begin{array}{c}\mathrm{N}^{\circ} \text { de } \\
\text { animais }\end{array}$ & $\begin{array}{c}\text { Coeficiente Médio } \\
\text { de Endogamia }(\%)\end{array}$ & $\begin{array}{c}\text { Média de F para animais } \\
\text { endogâmicos }(\%)\end{array}$ \\
\hline 1 & $1976-1979$ & 16.191 & 0,00 & 0,00 \\
2 & $1980-1983$ & 7.855 & 0,17 & 15,66 \\
3 & $1984-1987$ & 3.660 & 0,73 & 10,99 \\
4 & $1988-1991$ & 1.874 & 1,14 & 5,95 \\
5 & $1992-1995$ & 792 & 1,01 & 5,90 \\
6 & $1996-1999$ & 359 & 1,00 & 4,73 \\
7 & $2000-2003$ & 324 & 2,06 & 6,75 \\
8 & $2004-2007$ & 67 & 1,96 & 6,58 \\
\hline
\end{tabular}

Ainda na Tabela 2, observa-se que da sétima para a oitava geração houve um decréscimo no coeficiente médio de endogamia, ainda que fosse esperado um acréscimo, devido à redução do número de animais de uma geração para a outra. Isso indica que os acasalamentos entre parentes próximos têm sido evitados, ademais, nesse período o tamanho efetivo sofreu um acréscimo.

Quanto à contribuição genética dos ancestrais mais influentes, verificou-se que 10 e $50 \%$ da variabilidade genética de toda população foi decorrente dos 15 e 358 fundadores, respectivamente, de modo que o número efetivo de fundadores foi igual a 717. Devido aos baixos coeficientes de endogamia, esse número efetivo de fundadores tem se mostrado eficiente para a manutenção da variabilidade genética do rebanho.

A estimativa de herdabilidade direta para o peso aos 205 dias foi $0,11 \pm 0,02$ (Tabela 3). Dados inferiores aos estimados por Pimenta Filho et al. (2001) - $(0,35 \pm 0,08)$ para a mesma raça. Já Mucari \& Oliveira (2003) verificaram herdabilidade direta igual a 0,14 .

Ainda em relação ao P205, observou-se um valor muito baixo da herdabilidade materna $(0,01)$, similarmente ao que constataram Mucari \& Oliveira (2003). Isso indica baixa influência dos efeitos maternos nessa característica, portanto, dificuldade de ganho genético para esse efeito por meio de seleção. Entretanto, 
valores superiores a este foram constatados por Pimenta Filho et al. (2001) - $(0,39 \pm 0,11)$ e por Lira et al. (2008) - $(0,06 \pm 0,01)$.

A estimativa de herdabilidade direta para o P365 (Tabela 3) igual a $0,18 \pm$
0,02 foi inferior à encontrada por Pimenta Filho et al. (2001) - (0,26 \pm $0,02)$, para essa raça na Paraíba. Mucari e Oliveira, (2003) verificaram valor de herdabilidade igual a 0,08 .

Tabela 3. Estimativas dos componentes de variâncias $\left(\mathrm{kg}^{2}\right)$, e herdabilidades para os pesos (kg) aos 205 (P205), 365 (P365) e 550 (P550) dias de idade em bovinos da raça Guzerá do Nordeste brasileiro

\begin{tabular}{lccccc}
\hline Características & $\sigma_{\mathrm{a}}^{2}$ & $\sigma_{\mathrm{m}}^{2}$ & $\sigma_{\mathrm{p}}^{2}$ & $\mathrm{~h}_{\mathrm{d}}^{2}$ & $\mathrm{~h}_{\mathrm{m}}^{2}$ \\
\hline $\mathrm{P} 205$ & 51,45 & 4,99 & 471,97 & $0,11 \pm 0,02$ & $0,01 \pm 0,02$ \\
$\mathrm{P} 365$ & 175,40 & - & 948,25 & $0,18 \pm 0,02$ & - \\
$\mathrm{P} 550$ & 321,87 & - & $1.824,89$ & $0,18 \pm 0,03$ & - \\
\hline$\sigma_{\mathrm{a}}^{2} ; \sigma_{\mathrm{m}}^{2} ; \sigma_{\mathrm{p}}^{2} ; \mathrm{h}_{\mathrm{d}}^{2} ; \mathrm{h}_{\mathrm{m}}^{2}$ são, respectivamente, componentes de variância genética aditiva direta, genética \\
aditiva materna, variância fenotípica, herdabilidades direta e materna. Células representadas por (-), não \\
foram estimadas no presente trabalho.
\end{tabular}

Para P550, a herdabilidade foi de 0,18 \pm 0,03 , valor inferior ao verificado por Pimenta Filho et al. (2001) - (0,46 \pm 0,16). É interessante salientar que se tratam de trabalhos com banco de dados de tamanhos diferentes, além de metodologias diversas.

As herdabilidades diretas aqui estimadas para P365 e P550 apresentaram valores moderados. Com isso, constatou-se que há possibilidade de ganhos genéticos por meio da seleção direta para essas características.

Para P205, observou-se tendência genética direta significativa $(\mathrm{p}<0,01)$ e igual a $0,0084 \mathrm{~kg}$ por ano, o que representa um ganho de $0,2604 \mathrm{~kg}$ nos 29 anos estudados (Figura 3A). Ao considerar a média de P205 (147,58kg), a mudança genética anual para o resultado encontrado representa incremento de 0,05129\%/ano. Para a mesma raça, Mucari \& Oliveira (2003) verificaram ganho genético direto anual igual a $0,16 \mathrm{~kg} / \mathrm{ano}$, enquanto que Souza et al. (2004) observaram ganho genético direto anual de $0,11 \mathrm{~kg} / \mathrm{ano}$.
Para P365, a tendência genética direta mostrou-se significativa $(p<0,001)$ e igual a 0,0214kg/ano (Figura 3B), o que representa um incremento de $0,6634 \mathrm{~kg}$ no período de 31 anos. Em termos de mudança genética anual, esse resultado significa um aumento de $0,0504 \%$ por ano. Mucari \& Oliveira (2003) e Souza et al. (2004), para a mesma raça, constataram ganhos iguais a $0,04 \mathrm{e}$ $0,14 \mathrm{~kg} / \mathrm{ano}$ respectivamente.

A tendência genética direta para P550 foi significativa $(\mathrm{p}<0,001)$ e igual a 0,0255kg/ano (Figura 3C), o que incrementou em $0,7905 \mathrm{~kg}$ a característica nos 31 anos de estudo. Visto se tratar de mudança genética anual, esse resultado representa $0,0506 \%$ ao ano. Quando se compara $0,0255 \mathrm{~kg} / \mathrm{ano}$ aqui verificado com o observado por Mucari \& Oliveira (2003) - (0,34kg/ano), constata-se que o processo de seleção no rebanho estudado apresenta problemas gerenciais, já que o tamanho efetivo e o coeficiente de endogamia apresentam valores adequados. 

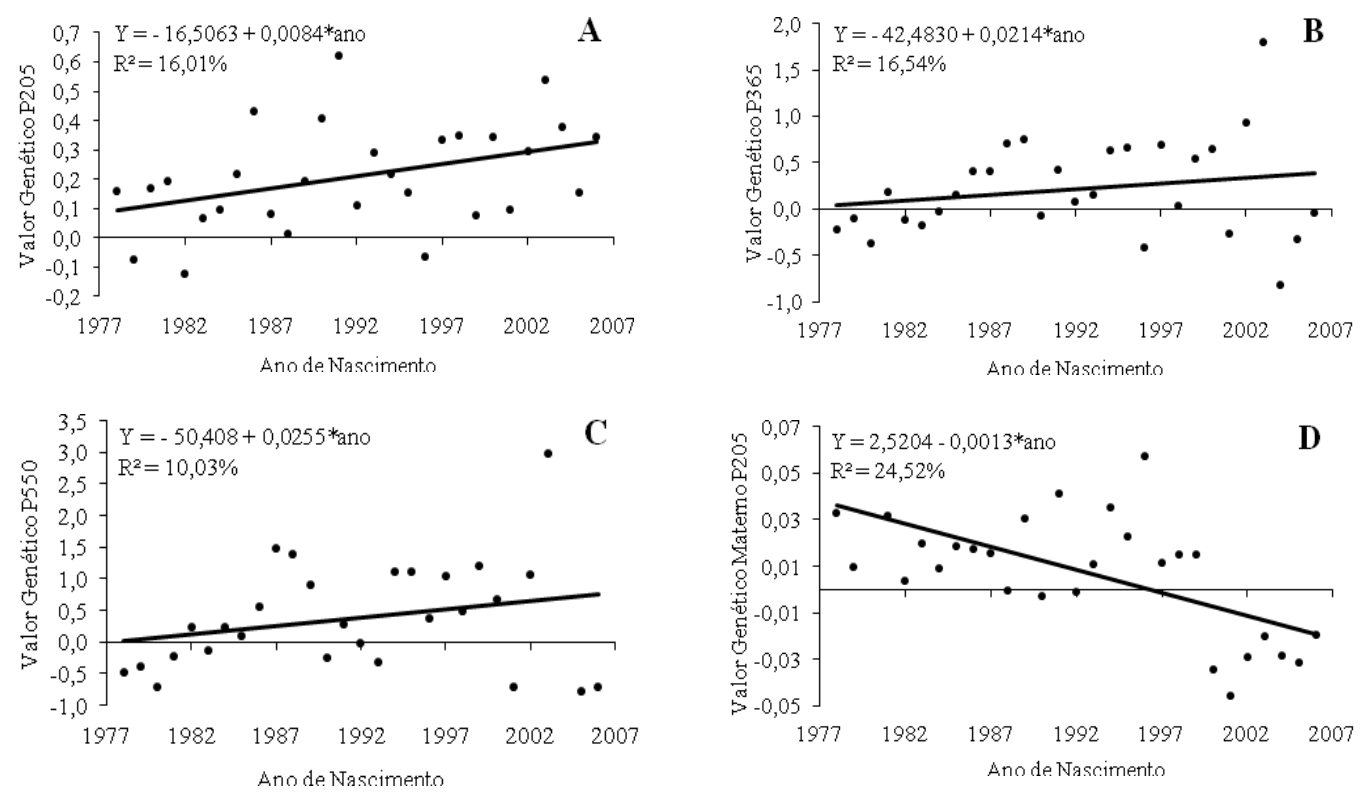

Figura 3. Tendências genéticas para o efeito direto para características P205 (A), P365 (B) e P550 (C) e para o efeito materno para P205 (D) de bovinos da raça Guzerá do Nordeste brasileiro

A tendência genética materna para o P205 foi significativa $(\mathrm{p}<0,01)$, igual a $0,0013 \mathrm{~kg} / \mathrm{ano}$ (Figura 3D). Souza et al. (2004) verificaram resultado semelhante e igual a $-0,01 \mathrm{~kg} /$ ano para a mesma raça, enquanto que Garcia et al. (2003), para a raça Nelore Mocho, observaram um valor de $-0,35 \mathrm{~kg} / \mathrm{ano}$. Tais valores negativos indicam que a contribuição dos genes maternos (do citoplasma do óvulo) sobre as características de crescimento é cada vez menor. Além do mais, a seleção para características de crescimento é feita geralmente nos reprodutores.

Os resultados obtidos para as tendências genéticas diretas para P205; P365 e P550 (Figura 3A, B e C) indicam ganhos genéticos ao longo dos anos, no entanto, estes ganhos estão bem abaixo de 1\%. Segundo Smith (1984), um programa de seleção é considerado eficaz quando o ganho genético anual está entre 1 a $3 \%$, quando se trata de estudos de campo, ainda que esses valores sejam teóricos e oscilem bastante.

Ao se considerar uma intensidade de seleção de 1,465 (retenção de $2 \%$ dos machos e $70 \%$ das fêmeas), as herdabilidades diretas da Tabela 3, desvios-padrão fenotípicos iguais a $21,72 \mathrm{~kg} ; 30,79 \mathrm{~kg}$ e $42,72 \mathrm{~kg}$ e o intervalo médio de gerações de oito anos, seria possível obter progressos genéticos por ano $\left(\Delta G=i \times h^{2} \times \sigma_{p} /\right.$ geração $)$ da ordem de 0,438; 1,015 e 1,408kg/ano, para P205; P365 e P550, respectivamente, o que corresponde a 0,$29 ; 0,50$ e $0,54 \%$ das médias do rebanho. É importante salientar que o uso mais intensivo desses animais permite reduzir o intervalo de geração pela metade, de modo a duplicar os ganhos genéticos por geração, o que causa um incremento considerável na receita do programa de melhoramento.

Os resultados aqui verificados estão em concordância com os observados por Biffani et al. (1999). Tais autores frisaram que, nas condições de criação típicas do Nordeste, os animais são 
selecionados pelos criadores com base mais nas características anatômicas e raciais do que pelo desempenho produtivo. No entanto, Malhado et al. (2005) afirmaram, com base no progresso genético constatado no rebanho Nelore da Bahia, que esse comportamento tem sido modificado.

As tendências fenotípicas para as características P205; P365 e P550 foram significativas $(\mathrm{p}<0,001) \quad \mathrm{e}$ respectivamente iguais a 1,$6584 ; 2,0829$ e 3,3364kg/ano (Figura 4A, B e C), o que representa incrementos de 51,41; 64,57 e $103,43 \mathrm{~kg}$ nas características,
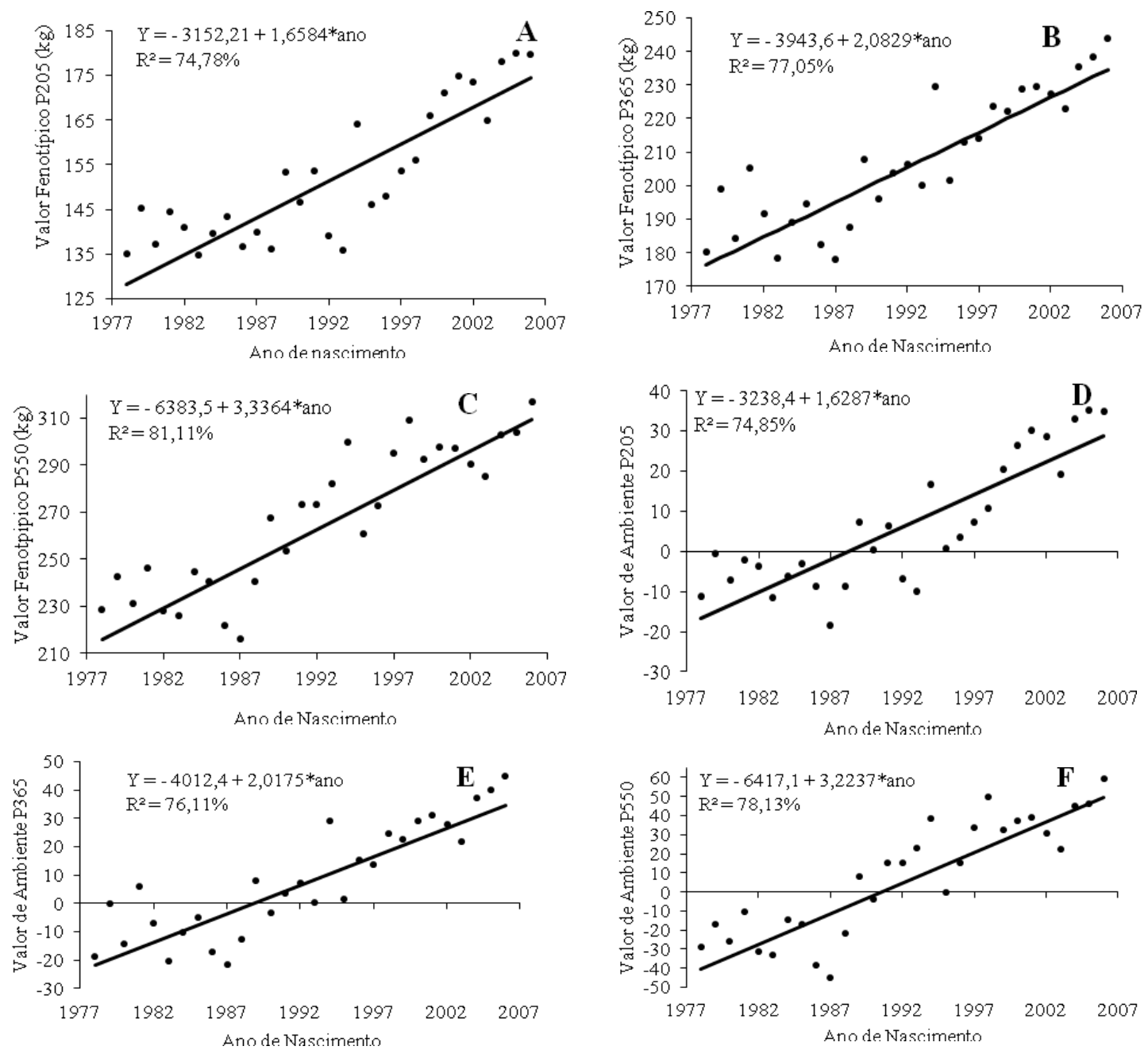

Figura 4. Tendências fenotípicas (A, B e C) e de ambiente (D, E e F) para as características P205, P365 e P550, respectivamente, de bovinos da raça Guzerá do Nordeste brasileiro durante o período analisado. Em termos de mudança fenotípica anual, esses valores representam para P205; P365 e P550 ganhos de 1,12; 1,03 e 1,28\%, respectivamente.

As tendências de ambiente para P205; P365 e P550 apresentaram-se significativas $(\mathrm{p}<0,001)$ e iguais a 1,6287 ; 2,0175 e 3,2237kg/ano (Figura 4D, E e F), a totalizar 50,$49 ; 62,54$ e $99,94 \mathrm{~kg}$ de incremento no período estudado, respectivamente. Ao se considerar a mudança anual de ambiente, esses valores representam, respectivamente, 1,1036; 1,0018 e $1,2317 \%$. 
Contata-se, pelos resultados obtidos (Figura 4A, B e C), que o ambiente para os rebanhos da raça Guzerá têm melhorado com o decorrer dos anos, o que indica que os produtores têm conseguido ganhos fenotípicos anuais significativos no crescimento dos animais. Logo, se percebe que esse progresso deve-se, em sua grande maioria, aos fatores de ambiente (Figura 4A, B e C), pois, os ganhos genéticos observados apesar de significativos foram baixos (Figura 3A, B e C).

A esse respeito, deve-se levar em consideração a tendência dos ganhos fenotípicos a atingirem o limite, se não houver seleção nas características avaliadas, ao longo dos próximos anos. $\mathrm{O}$ progresso genético obtido até $\mathrm{o}$ presente momento foi baixo e os ganhos fenotípicos obtidos atribuem-se aos efeitos de ambiente. Porém, a estimativa de herdabilidade com valor moderado e a ausência de problemas na estrutura populacional, evidenciam possibilidades de ganhos genéticos.

\section{AGRADECIMENTOS}

À Universidade Federal do Ceará pelo Curso de Doutorado, à CAPES pela bolsa do primeiro autor e à Associação Brasileira de Criadores de Zebu pela cessão dos dados.

\section{REFERÊNCIAS}

BIFFANI, S.; MARTINS FILHO, R.; GIORGETTI, A. Fatores ambientais e genéticos sobre o crescimento ao ano e ao sobreano de bovinos Nelore, criados no Nordeste do Brasil. Revista

Brasileira de Zootecnia, v.28, n.3, p.468-473, 1999.
BOICHARD, D.; MAIGNEL, L.; VERRIER, E. The value of using probabilities of gene origin to measure genetic variability in a population. Genetics, Selection and Evolution, v.29, p.5-23, 1997.

BOLDMAN, K.G.; KRIESE, L.A.; VAN VLECK, L.D.; VAN TASSELL, C.P; KACHMAN, S.D. "A manual for the use of MTDFREML”. ARS, USDA, Clay Center, NE, USA, 1995.

CAIRES, D.; SOUZA, L.; MALHADO, C.; CARNEIRO, P.; MARTINS FILHO, R. Tendência genética e fenotípica para características de crescimento em bovinos da raça Indubrasil no estado do Sergipe. Revista Brasileira de Saúde e Produção Animal [Online], v.10, n.4, p.813-820, 2009.

CARNEIRO, P.L.S.; MALHADO, C.H.M.; MARTINS FILHO, R.; CARNEIRO, A.P.S.; TORRES, R.A.; SILVA, F.F. A raça Indubrasil no nordeste brasileiro: melhoramento e estrutura populacional. Revista

Brasileira de Zootecnia, v.38, n.12, p.2327-2334, 2009.

FARIA, F.J.C.; VERCESI FILHO, A.E.; MADALENA, F.E.;

JOSAHKIAN, L.A. Estrutura populacional da raça Nelore Mocho. Arquivo Brasileiro de Medicina Veterinária e Zootecnia, v.54, p.501509, 2002.

GARCIA, F.Q.; FERRAZ FILHO, P.B.; SOUZA, J.C.; SILVA, L.O.C.

Tendências dos efeitos genéticos diretos e maternos do peso a desmama em bovinos da raça Nelore mocha na região pecuária Campo Grande e Dourados Mato Grosso do Sul. Archives of Veterinary Science, v.8, n.1, p.93-97, 2003. 
GUTIÉRREZ, J.P.; GOYACHE, F. A note on ENDOG: a computer program for monitoring genetic variability of populations using pedigree information. Journal of Animal Breeding and Genetics, v.122, n.3. p.172-176, 2005.

LIRA, T.; ROSA, E.M.; GARNERO, A.V. Parâmetros genéticos de características produtivas e reprodutivas em zebuínos de corte (revisão). Ciência Animal Brasileira, v.9, p.1-22, 2008.

MADUREIRA, A.P.; OLIVEIRA H.N.; ROSA, G.J.M.; BEZERRA, L.F.; Marques, L.F.A. Inferência bayesiana na predição de valores genéticos do peso aos 365 dias de bovinos de corte. Archivos de Zootecnia, v.58, n.222, p.265-275, 2009.

MALHADO, C.H.M.; CARNEIRO, P.L.S.; MARTINS FILHO, R.; AZEVEDO, D.M.M.R.; FACÓ, O.; MACHADO, C.H.C.; PICCININ, A.; SOUZA, J. C. Tendência e Parâmetros Genéticos para o Peso aos 205 Dias de Idade em Bovinos da Raça Nelore Mocho no Estado da Bahia. Revista Científica de Produção Animal, v.7, p.28-34, 2005.

MALHADO, C.H.M.; RAMOS, A. A.; CARNEIRO, P.L.S.; AZEVEDO, D.M.M.R.; MARTINS FILHO, R.; SOUZA, J.C. Melhoramento e estrutura populacional de bubalinos da raça Mediterrâneo no Brasil. Pesquisa Agropecuária Brasileira, v.43, p.215220, 2008a.

MALHADO, C.H.M.; CARNEIRO, P.L.S.; PEREIRA, D.G.; MARTINS FILHO, R.; SOUZA, J.C. Progresso genético e estrutura populacional do rebanho Nelore no Estado da Bahia. Pesquisa Agropecuária Brasileira, v.43, n.9, p.1163-1169, 2008b.
MUCARI, T.B.; OLIVEIRA, J.A. Análise genético-quantitativa de pesos aos 8, 12, 18 e 24 meses de idade em um rebanho da raça Guzerá. Revista Brasileira de Zootecnia, v.32, n.6, p.1604-1613, 2003. Suppl.1.

PACHECO, A.; QUIRINO, C.R.; PINHEIRO, O.L.V.M.; ALMEIDA, J.V.C. Medidas morfométricas de touros jovens e adultos da raça Guzerá. Revista Brasileira de Saúde e Produção Animal [Online],. v.9, n.3, p.426-435, 2008.

PIMENTA FILHO, E.C.; MARTINS, G.A.; SARMENTO, J.L.R.

Estimativas de herdabilidade de efeitos direto e materno de características de crescimento de bovinos Guzerá, no Estado da Paraíba. Revista Brasileira de Zootecnia, v.30, n.4, p.1220-1223, 2001.

SMITH, C. Rates of genetic change in farm livestock. Research

Devolopment Agricutural, v.1, n.2, p.79-85, 1984.

SOUZA. J.C.; MALHADO, C.H.M.; SILVA, L.O.C.; LEAL, T.L. GOMES, C.M.; JACINTO, E.J.; FERRAZ FILHO, P.B. Parâmetros e Tendência Genética em bovinos da raça Guzerá na Microrregião Mata e Agreste no Nordeste do Brasil, Revista Acadêmica: Ciências Agrárias e Ambientais, v.2, n.2, p.47-52, 2004.

VERCESI FILHO, A.E.; FARIA, F.J.C.; MADALENA, F.E.; JOSAHKIAN, L.A. Estrutura populacional do rebanho Tabapuã registrado no Brasil. Arquivo Brasileiro de Medicina Veterinária e Zootecnia, v.54, p.609-617, 2002a. 
Rev. Bras. Saúde Prod. Anim., Salvador, v.13, n.4, p.1032-1043 out./dez., 2012 http://www.rbspa.ufba.br ISSN 15199940

VERCESI FILHO, A.E.; FARIA, F.J.C.; MADALENA, F.E.;

JOSAHKIAN, L.A. Estrutura populacional do rebanho Indubrasil registrado no Brasil. Archivos

Latinoamericano de Produccíon Animal, v.10, n.2, p.86-92, 2002 b.

YOKOO, M.J.I.; ALBUQUERQUE, L.G.; LÔBO, R.B.; SAINZ, R.D.; CARNEIRO JÚNIOR, J.M.; BAZERRA, L.A.F.; ARAÚJO, F.R.C. Estimativas de parâmetros genéticos para altura do posterior, peso e circunferência escrotal em bovinos da raça Nelore. Revista Brasileira de Zootecnia, v.36, n.6, p.1761-8, 2007.
YOKOO, M.J.; MAGNABOSCO, C.U.; ROSA, G.J.M.; LÔBO, R.B.;

ALBUQUERQUE, L.G. Características reprodutivas e suas associações com outras características de importância econômica na raça Nelore. Arquivo Brasileiro de Medicina Veterinária e Zootecnia, v.64, n.1, p.91-100, 2012.

Data de recebimento: 13/03/2012 Data de aprovação: 26/10/2012 